\title{
Studies on Anti-Hepatoma Effect of Gan-Ai-Xiao Decoction
}

\author{
Jian-Lei Yuan ${ }^{1 *}$, Shu-Mei Wang ${ }^{2}$, Tao Lan${ }^{1}$, Jian-Zhong Liu ${ }^{1}$, Gui-Hua Wang ${ }^{1}$, \\ Qing-Sen Sun ${ }^{1}$ and Hui Chen ${ }^{1}$ \\ ${ }^{1}$ Department of Hepato-Biliary-Pancreatic, ${ }^{2}$ Department of Pharmacy, People Hospital of Cangzhou City, Cangzhou Hebei \\ 061000, PR China
}

*For correspondence: Email: jlyuan_2015@163.com; Tel: +86 0317-3521817

\begin{abstract}
Purpose: To explore the anti-hepatoma effect of Gan-Ai-Xiao Decoction (GAXD), a folk remedy. Methods: High performance liquid chromatography (HPLC) was used to identify the major chemical components of GAXD ethanol extract (EE). The cytotoxic effect of GAXD EE against HepG2 cells was measured by methyl thiazolyl tetrazolium (MTT) assay. Flow cytometry and Western blot were used to study the effect of GAXD EE on apoptosis and apoptotic proteins (Bcl-2, Bax and caspase-3) in HepG2 cells. Xenograft assay was used to evaluate the anti-hepatoma effect of GAXD EE in vivo.

Results: Four components were identified in GAXD EE by HPLC. The results of MTT and flow cytometry assays indicated that GAXD EE significantly reduced HepG2 cells viability $(p<0.05)$ and induced its apoptosis. The results of Western blot assay suggested that GAXD EE down-regulated the expression of anti-apoptotic protein (BCl-2) and up-regulated the expression of pro-apoptotic proteins (Bax and caspase-3) in HepG2 cells. Furthermore, the results of xenograft assay showed that GAXD EE significantly inhibited the growth of HepG2 cells-induced tumor $(p<0.05)$ without any effect on the body weight of nude mice.

Conclusion: GAXD has anti-hepatoma activity, and the mechanism is associated with apoptosis. Keywords: Gan-Ai-Xiao Decoction, Anti-hepatoma, Flow cytometry, Western blot, Xenograft, HepG2 cells, Apoptosis
\end{abstract}

Tropical Journal of Pharmaceutical Research is indexed by Science Citation Index (SciSearch), Scopus, International Pharmaceutical Abstract, Chemical Abstracts, Embase, Index Copernicus, EBSCO, African Index Medicus, JournalSeek, Journal Citation Reports/Science Edition, Directory of Open Access Journals (DOAJ), African Journal Online, Bioline International, Open-J-Gate and Pharmacy Abstracts

\section{INTRODUCTION}

The liver plays an important role in metabolism and has many functions in human life, such as detoxification, glycogen storage and plasma protein synthesis. However, patients with liver cancer are facing afunction of the liver. Nowadays, the people's lifestyles such as obesity [1], smoking [2] and alcohol drinking [3] enhance the incidence of hepatoma. Hepatoma is the second leading cause of cancer mortality worldwide [4] and a number of therapies have been used to decrease the mortality of patients with hepatoma, such as surgical treatment [5], interventional therapy [6-8], biotherapy [9], radiotherapy [10,11], chemotherapy [12], adjunctive traditional Chinese medicine (TCM) therapy $[13,14]$. According to clinical observation, adjunctive TCM therapy has unique advantages, such as stabilizing patient condition, low toxicity and side effect, improving clinical symptoms, prolonging patients' survival time and low cost.

GAXD, a folk medicine, is composed of Stigma Maydis, Kummerowia Herbal, Gleditsiae Spina, Astragali Radix, Poria, Glycyrrhizae Radix (Table 1). GAXD has been used to cure hepatoma with a long history in Southwestern China, such as Tianshui, Baoji and Bazhong, but there were not any study reports about its anti-hepatoma effect. 
In this work, we identified the major chemical components and studied anti-hepatoma effect of GAXD by HPLC, MTT, flow cytometry, western blot and xenograft assays.

\section{EXPERIMENTAL}

\section{Plant materials}

Stigma Maydis, Kummerowia Herbal, Gleditsiae Spina, Astragali Radix, Poria and Glycyrrhizae Radix were collected from Sichuan, Henan, Shanxi and Jiangxi in 2010. Their original plants were identified by Department of Pharmacy, People Hospital of Cangzhou city, Cangzhou Hebei. All air-dried plant materials were used to form GAXD. A series of voucher specimen (2010022-2010027/PHCZCHB) were deposited in Department of Pharmacy, People Hospital of Cangzhou city, Cangzhou Hebei for future reference.

\section{Chemicals and reagents}

HPLC grade methanol was purchased from Fisher (Fisher Scientific, USA). Analytical grade DMSO, phosphoric acid and ethanol were purchased from Sinopharm Chemical Reagent Co. (Shanghai, China). Ultra-pure water was obtained from Milli-Q Advantage A10 (Millipore Crop., MA, USA). Isoorientin, quercetin, luteolin and apigenin were purchased from Shanghai shifeng biological technology Co. Itd (Shanghai, China) and the National Institute for the Control of Pharmaceutical and Biological Products (Beijing, China). Bcl-2, Bax and caspase-3 monoclonal antibodies were obtained from Abcam Co. (Hong Kong, China). Goat antirabbit/HRP was obtained from Shanghai Hao Yang Biotechnology Co. (Shanghai, China).

\section{Animals}

Nude mice (5 - 6 weeks old) were purchased from the SLRC Laboratory Animal Company (Shanghai, China). All animal treatments were strictly in accordance with the international ethical guidelines and the National Institutes of Health Guide concerning the Care and Use of
Laboratory Animals [15]. Experiments were carried out with the approval of the Animal Experimentation Ethics Committee of People Hospital of Cangzhou city, Cangzhou Hebei.

\section{Preparation of GAXD ethanol extract}

All crude drugs of GAXD were powdered together according to the composition shown in Table 1. The powder was extracted 3 times $(6 \mathrm{~h}$ $\times 3$ ) with $75 \%$ ethanol at room temperature. Evaporation of the $75 \%$ ethanol under reduced pressure provided the GAXD ethanol extract (EE) $(13.6 \mathrm{~g} / 100 \mathrm{~g})$, which was diluted with $0.5 \%$ DMSO to obtain the required concentrations for the various tests.

\section{Identification of major chemical components of GAXD EE}

The GAXD EE was dissolved in methanol to get appropriate concentrations for HPLC analysis. The identification of chemical components of GAXD EE was performed with Agilent Technologies 1100 system (Agilent Crop., MA, USA). The chromatography was carried out on an Eclipse XDB-C18 column $(4.6 \mathrm{~mm} \times 250 \mathrm{~mm}$, $5 \mu \mathrm{m})$. The mobile phase was composed of methanol (solvent $\mathrm{A}$ ) and $0.2 \%$ phosphoric acid (solvent B): 0 - 20 min $(20-45 \%, A), 20-30$ $\min (45-70 \%, A), 30-38 \min (70-100 \%, A)$. The column temperature was $30{ }^{\circ} \mathrm{C}$. The injection volume was $15 \mu \mathrm{L}$. The flow rate was 1 $\mathrm{mL} / \mathrm{min}$. The detection wavelength was $355 \mathrm{~nm}$.

\section{Cell culture}

Human hepatoma cell line (HepG2) was obtained from American Type Culture Collection (Manassas, Virginia, VA, USA). The cells were cultured in RPMI-1640 medium supplemented with antibiotics $(100 \mu \mathrm{g} / \mathrm{mL}$ streptomycin and 100 $\mathrm{U} / \mathrm{mL}$ penicillin) and $10 \%$ fetal bovine serum. The cells were cultured with a humid atmosphere of $5 \% \mathrm{CO}_{2}$ and $95 \%$ air at $37{ }^{\circ} \mathrm{C}$. Then the logarithmic-growth phase cells were used to evaluate the anti-hepatoma effect of GAXD EE.

Table 1: Composition of Gan-Ai-Xiao Decoction (GAXD)

\begin{tabular}{lllc}
\hline Plant & Family & Original plant & Weight (g) \\
\hline Stigma Maydis & Poaceae & Zea mays L. & 30 \\
Kummerowia Herbal & Leguminosae & Kummerowia striata (Thunb.) Schindl & 30 \\
Gleditsiae Spina & Leguminosae & Gleditsia sinensis Lam & 15 \\
Astragali Radix & Leguminosae & Astragalus membranaceus (Fisch.) Bunge. & 15 \\
Poria & Polyporaceae & Wolfiporia cocos (Schw.) Ryv.\&Gibn & 10 \\
Glycyrrhizae Radix & Leguminosae & Glycyrrhiza uralensis Fisch & 5 \\
\hline
\end{tabular}




\section{MTT assay}

HepG2 cells $\left(1 \times 10^{4} / 0.2 \mathrm{~mL}\right)$ were seeded on 96 -well plates and incubated for $24 \mathrm{~h}$. Then cells were separately treated with GAXD EE (20, 40 and $80 \mu \mathrm{g} / \mathrm{mL}$ ) and $0.05 \%$ DMSO (control) for $48 \mathrm{~h}$. Subsequently, MTT assay was performed using a standard protocol and the absorbance of both control (Ac) and treated (At) samples was measured at $490 \mathrm{~nm}$ in a microplate reader (Multiskan FC, Thermo, MA, USA). Inhibition was calculated as in Eq 1 [16]:

Inhibition $(\%)=\{(\mathrm{Ac}-\mathrm{At}) / \mathrm{Ac}\} 100$

\section{Apoptosis assay by flow cytometry}

HepG2 cells, separately treated with GAXD EE $(20,40$ and $80 \mu \mathrm{g} / \mathrm{mL})$ and $0.05 \%$ DMSO (control) for $48 \mathrm{~h}$, were harvested by centrifugation. Then the cells were washed with cold phosphate buffered saline (PBS) twice, stained with Annexin V-FITC and propidium iodide (PI) according to the manufacturer's instructions. Subsequently, the stained cells were analyzed by flow cytometry on a FACScalibur flow cytometer (BD Biosciences, San Jose, CA, USA).

\section{Western blot analysis}

After treatment with GAXD EE (20, 40 and 80 $\mu \mathrm{g} / \mathrm{mL}$ ) and $0.05 \%$ DMSO (control) for $48 \mathrm{~h}$, HepG2 cells were harvested and their total proteins were extracted. The concentration of total proteins was determined by the Enhanced BCA Protein Assay kit (Beyotime, Haimen, Chian). About $40 \mu \mathrm{g}$ total proteins were separated by SDS/PAGE and blotted on PVDF membrane. Then PVDF membranes with target protein were probed with anti-Bcl-2, Bax and caspase-3 rabbit polyclonal IgG and subsequently with goat anti-rabbit/HRP, and detected by chemiluminescence. Antibody directed against $\beta$-actin was used to measure protein loading.

\section{Xenograft assay}

Nude mice ( 5 - 6 weeks old) were randomly divided into two groups, control and treatment groups $(n=8)$. HepG 2 cells $\left(2 \times 10^{6}\right.$ cells per nude mouse) were injected in the right flank of mice subcutaneously. When the HepG2-induced tumors grew to about $2-3 \mathrm{~mm}$ in diameter, the control and treatment groups were separately treated with $0.05 \%$ DMSO and GAXD EE (100 $\mathrm{mg} / \mathrm{kg}$ ) for 15 days by gavage. The tumor sizes (width and length) and body weight of nude mice were measured in 5th, 10th and 15th days by a vernier caliper. The tumor volumes were calculated as in Eq 2 [17]. At last, all animals were sacrificed by injecting chloral hydrate.

Volume $=\left(\right.$ width $^{2} \times$ length $) / 2$

\section{Statistical analysis}

All data are presented as mean \pm standard deviation (SD). The difference between groups was analyzed by two-tailed Student's t-test in SPSS 21.0. When $p$-value was less than 0.05, the differences were considered as statistically significant.

\section{RESULTS}

\section{Major chemical components of GAXD EE}

As shown in Figure 1, four components, isoorientin, quercetin, luteolin and apigenin, were identified in GAXD EE according to standard substance by HPLC.

\section{Cytotoxic effects of GAXD EE on HepG2 cells}

The results of MTT assay indicated that GAXD EE $(20,40$ and $80 \mu \mathrm{g} / \mathrm{mL})$ significantly $(p<0.05)$ reduced the HepG2 cells viability in a dosedependent manner, compared with control. The results are shown in Figure 2.

\section{Effects of GAXD EE on apoptosis of HepG2 cells}

As depicted in Figure 3, the results of flow cytometry assay indicated that GAXD EE (20, 40 and $80 \mu \mathrm{g} / \mathrm{mL}$ ) induced the apoptosis of HepG2 cells in a dose-dependent manner.

\section{Effects of GAXD EE on apoptotic proteins of HepG2 cells}

The results of western blot assay suggested that GAXD EE (20, 40 and $80 \mu \mathrm{g} / \mathrm{mL})$ obviously down-regulated the expression of anti-apoptotic protein (Bcl-2) and up-regulated the expression of pro-apoptotic proteins (Bax and caspase-3) in a dose-dependent manner. The results are shown in Figure 4.

\section{Anti-tumor effects of GAXD EE on HepG2 cells-induced tumor}

Xenograft assay of nude mice was used to evaluate the anti-tumor effect of GAXD EE on HepG2 cells-induced tumor in vivo. Tumor volume and body weight of nude mice were used 
to evaluate the anti-tumor effect. As depicted in Figure 5, GAXD EE significantly $(p<0.05)$ inhibited the growth of HepG2 cells-induced tumor without any effect on the body weight of the mice, compared with control.

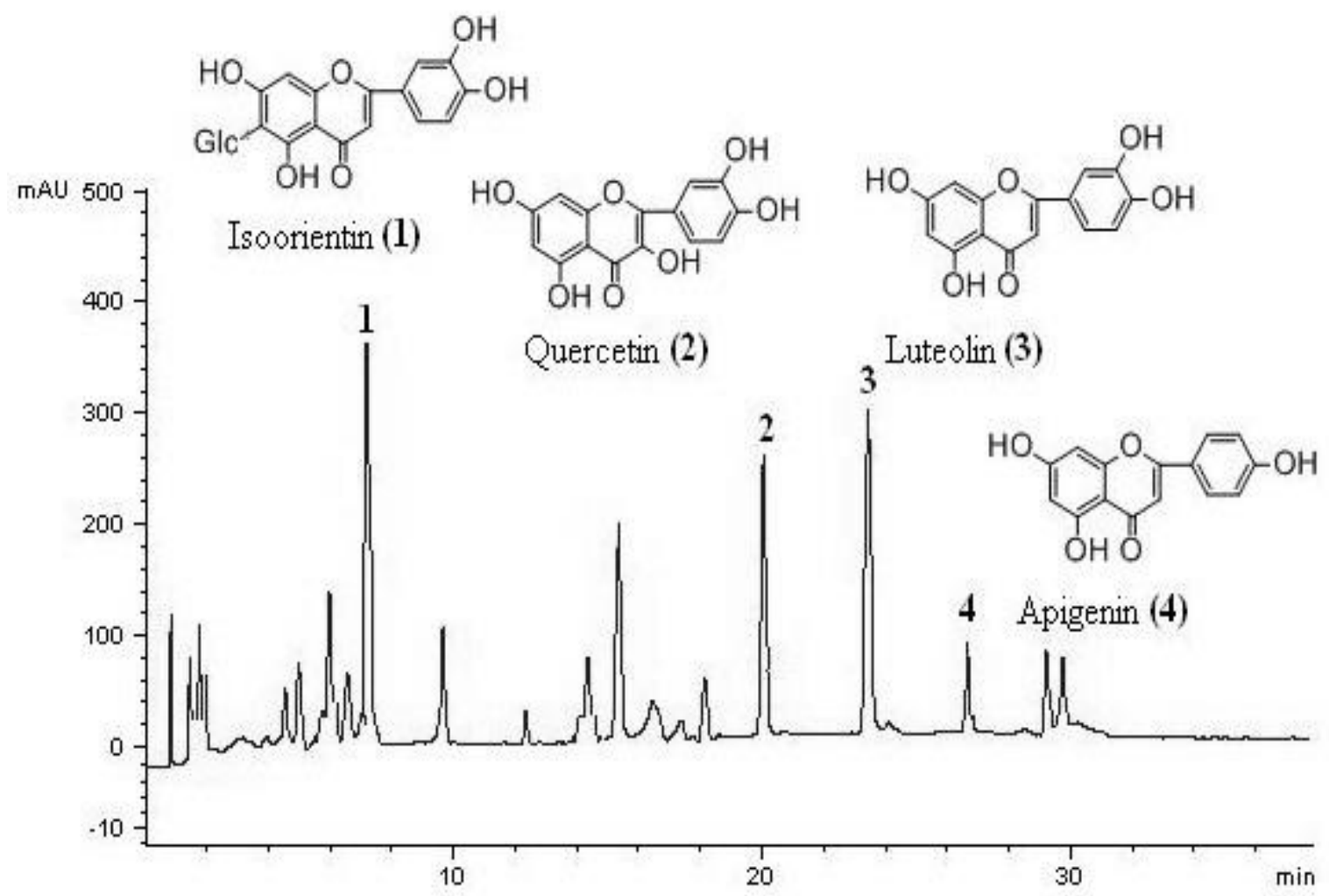

Figure 1: Chromatogram showing the major chemical components of GAXD ethanol extract

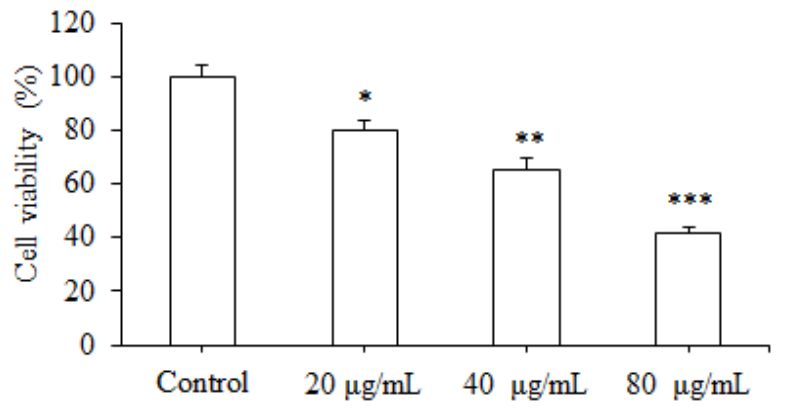

Figure 2: Cytotoxic effect of GAXD ethanol extract on HepG2 cells. HepG2 cells were treated with $0.05 \%$ DMSO (control) and GAXD ethanol extract (20, 40 and $80 \mu \mathrm{g} / \mathrm{mL})$ for $48 \mathrm{~h}$; ${ }^{*} p<0.05,{ }^{* *} p<0.01,{ }^{* * *} p<$ 0.001 , compared with control

\section{DISCUSSION}

In this work, we research the major chemical components and anti-hepatoma effect of GAXD by HPLC, MTT, flow cytometry, Western blot and xenograft assays for the first time. The study on identification of major chemical components shows that what the active components are in GAXD.
MTT assay, a common method, is used to evaluate the cytotoxic effect of drug against cultured cells in vitro by determining cells viability $[18,19]$. Viable cells induce MTT to generate the purple-blue formazan precipitate, but dead cells lose this function. The absorbance of formazan dissolved in DMSO is used to analyze the cytotoxic effect of drugs on cells. The result of MTT assay indicated that GAXD EE had significant cytotoxic activity against HepG2 cells (Figure 2).

Flow cytometry assay $[20,21]$ was used to study whether the cytotoxic activity of GAXD EE against HepG2 cells was associated with apoptosis. The cells in early apoptosis were stained with Annexin V-FITC and cells in late apoptosis were stained with Annexin V-FITC and $\mathrm{PI}$. Subsequently, cells were analyzed by flow cytometry and different kinds of cells including dead cells, viable cells, cells in early apoptosis and cells in late apoptosis were counted respectively. According to the results of counting in flow cytometry, we can easily analyze whether drugs induce apoptosis of cells. The results of flow cytometry suggested that the cytotoxic activity of GAXD EE against HepG2 cells was associated with apoptosis (Figure 3 ). 

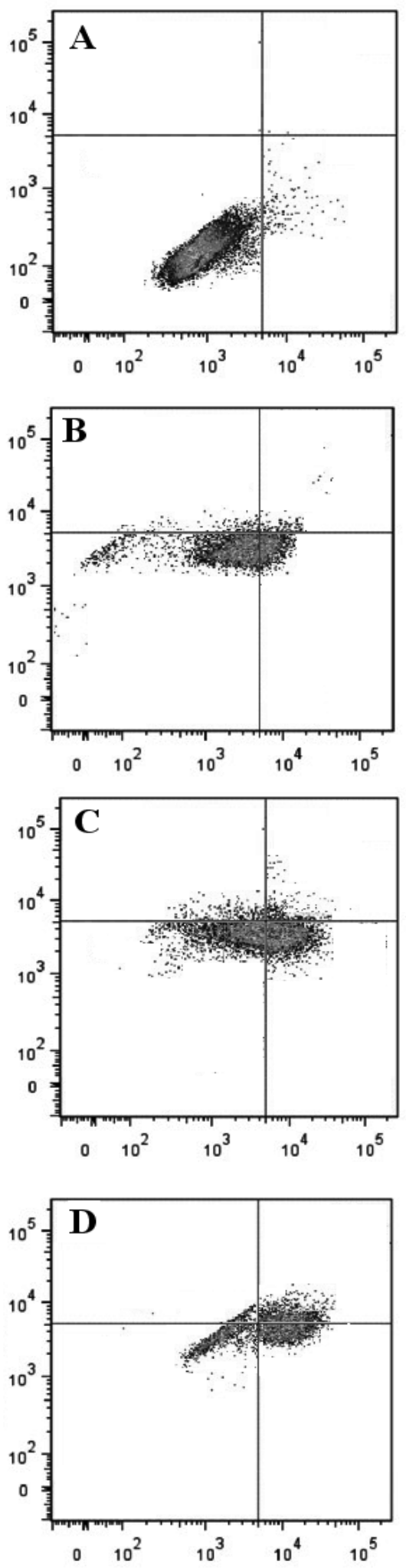

Figure 3: Effects of GAXD ethanol extract on apoptosis of HepG2 cells. HepG2 cells were treated with $0.05 \%$ DMSO (control) and GAXD ethanol extract (20, 40 and $80 \mu \mathrm{g} / \mathrm{mL}$ ) for $48 \mathrm{~h}$; A, B, C, D stood for $0.05 \%$ DMSO, 20, 40 and $80 \mu \mathrm{g} / \mathrm{mL}$ GAXD ethanol extract respectively
$\mathrm{Bcl}-2$

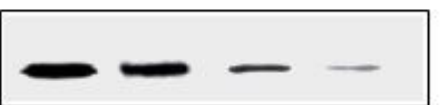

Bax

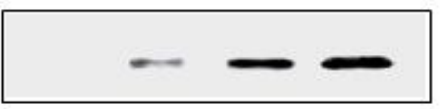

caspase-3

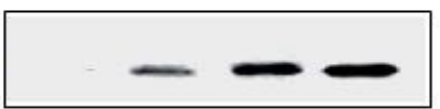

$\beta$-actin

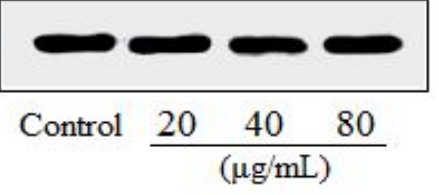

Figure 4: Effect of GAXD ethanol extract on apoptotic proteins (Bcl-2, Bax and caspase-3) of HepG2 cells. HepG2 cells were separately treated with $0.05 \%$ DMSO (control) and GAXD ethanol extract (20, 40 and $80 \mu \mathrm{g} / \mathrm{mL}$ ) for $48 \mathrm{~h}$
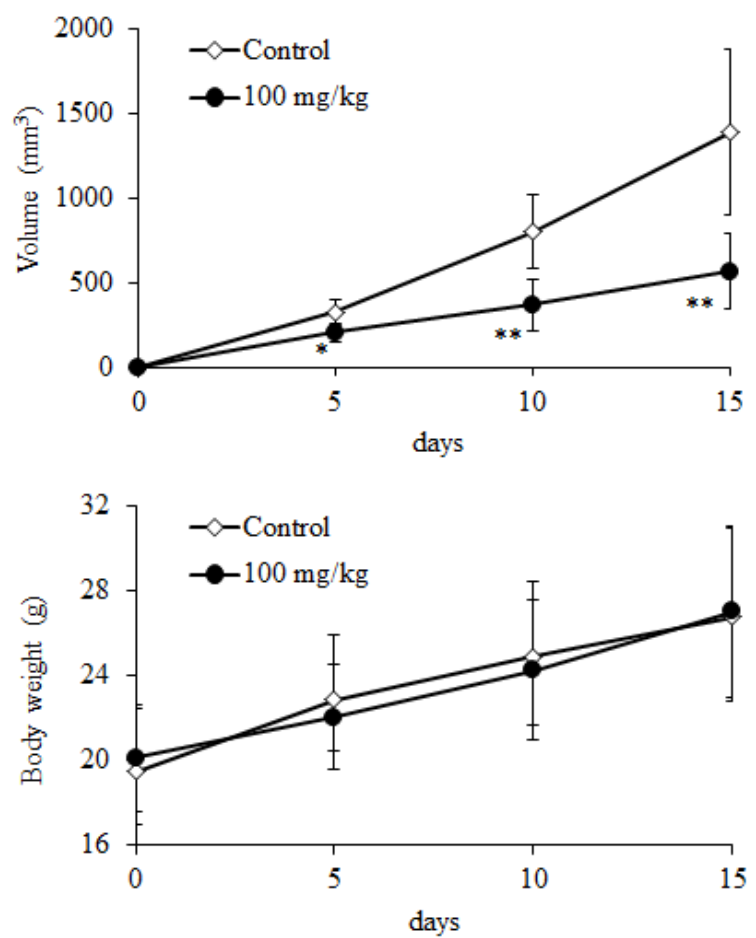

Figure 5: Anti-tumor effect of GAXD ethanol extract on HepG2 cells-induced tumor. Nude mice were treated with $0.05 \%$ DMSO (control) and GAXD ethanol extract (100 mg/kg) by gavage; * $p<0.05$, ** $p<0.01$, compared with control.

The results of MTT and flow cytometry assays indicated that GAXD indeed have anti-hepatoma activity, associated with apoptosis. Western blot assay was used to study the effects of GAXD on apoptotic proteins, which were immediately related to apoptosis of cells. The apoptotic proteins were a research hotspot in the aspect of anti-tumor mechanism [22,23]. Bcl-2 protein 
inhibits apoptosis of tumor cells, and Bax and caspase-3 proteins induce apoptosis of tumor cells [24]. As depicted in Figure 4, GAXD EE down-regulated the expression of anti-apoptotic protein (Bcl-2), and increased the expression of pro-apoptotic proteins (Bax and caspase-3). Namely, the anti-hepatoma mechanisms of GAXD were associated with apoptosis.

Finally, the xenograft assay was used to verify the anti-tumor effect of GAXD in vivo. The results of xenograft assay indicated that GAXD EE significantly inhibited the growth of HepG2 cellsinduced tumor without any effect on the body weight of nude mice.

\section{CONCLUSION}

GAXD shows anti-hepatoma activity in vitro and in vivo by inducing the apoptosis of HepG2 cells, associated with down-regulating the expression of anti-apoptotic protein (Bcl-2) and increasing the expression of pro-apoptotic proteins (Bax and caspase-3). Additionally, this work provides the evidences to support that GAXD is used to cure hepatoma. However, further studies to elucidate the anti-hepatoma mechanisms of GAXD are required.

\section{REFERENCES}

1. Devkota S, Turnbaugh PJ. Cancer: An acidic link. Nature 2013; 499(7456): 37-38.

2. Liu YM, Shen YP, Liu N, Hu WB, Liu W. Meta-analysis of the association between smoking and liver cancer. Mod Prevent Med 2010; 37(20): 3801-3807.

3. Chen CJ, Liang KY, Chang A, Chang YC, Lu SN, Liaw $Y F$, Chang WY, Sheen MC, Lin TM. Effects of hepatitis $B$ virus, alcohol drinking, cigarette smoking and familial tendency on hepatocellular carcinoma. Hepatology 1991; 13(3): 398-406.

4. Lafaro KJ, Demirjian AN, Pawlik TM. Epidemiology of hepatocellular carcinoma. Surg Oncol Clin N Am 2015; 24(1): 1-17.

5. Poon RT, Fan ST. Hepatectomy for hepatocellular carcinoma: patient selection and postoperative outcome. Liver Transpl 2004; 10(S2): S39-S45.

6. Kawasoe H, Eguchi Y, Mizuta T, Yasutake T, Ozaki I, Shimonishi T, Miyazaki K, Tamai T, Kato A, Kudo S, et al. Radiofrequency ablation with the real-time virtual sonography system for treating hepatocellular carcinoma difficult to detect by ultrasonography. J Clin Biochem Nutr 2007; 40: 66-72.

7. Cheng $B Q$, Jia $C Q$, Liu $C T$, Fan $W$, Wang $Q L$, Zhang $Z L$, $\mathrm{Yi} \mathrm{CH}$. Chemoembolization combined with radiofrequency ablation for patients with hepatocellular carcinoma larger than $3 \mathrm{~cm}$ : a randomized controlled trial. JAMA-J Am Med Assoc 2008; 299(14): 1669-1677.

8. Kurokohchi K, Watanabe S, Yoneyama H, Deguchi A, Masaki T, Himoto T, Miyoshi H, Mohammad HS, Kitanaka A, Taminato $T$, et al. A combination therapy of ethanol injection and radiofrequency ablation under general anesthesia for the treatment of hepatocellular carcinoma. World J Gastroenterol 2008; 14(13): 2037-2043.

9. Sun J, Bie B, Zhang S, Yang J, Li Z. Long non-coding RNAs: critical players in hepatocellular carcinoma. Int J Mol Sci 2014; 15(11): 20434-20448.

10. Seo YS, Kim JN, Keum B, Park S, Kwon YD, Kim YS, Jeen YT, Chun HJ, Kim CY, Kim CD, et al. Radiotherapy for 65 patients with advanced unresectable hepatocellular carcinoma. World J Gastroenterol 2008; 14(15): 2394-2400.

11. Dawson LA, Eccles C, Bissonnette JP, Brock KK. Accuracy of daily image guidance for hypofractionated liver radiotherapy with active breathing control. Int J Radiat Oncol Biol Phys 2005; 62(4): 1247-1252.

12. Konno T. Targeting chemotherapy for hepatoma: arterial administration of anticancer drugs dissolved in Lipiodol. Eur J Cancer 1992; 28(2-3): 403-409.

13. He YJ, Wang J, Liu XL, Zhang L, Yi G, Li CW, He X, Wang $P$, Jiang $H$. Toosendanin inhibits hepatocellular carcinoma cells by inducing mitochondria-dependent apoptosis. Planta Med 2010; 76(13): 1447-1453.

14. Fei M, Lu MD, Wang Y, Zhao YM, He S, Gao SF, Ke Q, Liu YH, Li P, Cui XP, et al. Arsenic trioxide-induced growth arrest of human hepatocellular carcinoma cells involving $\mathrm{FOXOЗa} \mathrm{expression} \mathrm{and} \mathrm{localization.}$ Med Oncol 2009; 26(2): 178-185.

15. CPCSEA guidelines for laboratory animal facility. Indian J Pharmacol 2003; 35: 257-274.

16. Liu HL, Zhu YJ, Zhang T, Zhao ZG, Zhao Y, Cheng $P$, Li $H$, Gao $H$, Su XM. Anti-tumor effects of atractylenolide $I$ isolated from Atractylodes macrocephala in human lung carcinoma cell lines. Molecules 2013; 18: 13357-13368.

17. Ma YS, Weng SW, Lin MW, Lu CC, Chiang JH, Yang JS. Antitumor effects of emodin on LS1034 human colon cancer cells in vitro and in vivo: Roles of apoptotic cell death and LS1034 tumor xenografts model. Food Chem Toxicol 2012; 50: 1271-1278.

18. Hatok J, Babusikova E, Matakova T, Mistuna D, Dobrota $D$, Racav $P$. In vitro assays for the evaluation of drug resistance in tumor cells. Clin Exp Med 2009; 9(1): 17.

19. Enomoto T, Takao S, Mure H, Baba M, Aikou T. MTThybird assay incorporates the advantages of both clonogenic and MTT assay radiosensitivity testing for fresh tumor samples. J Exp Clin Cancer Res 1997; 16(3): 273-280.

20. Xie QC, Yang YP, Wang ZY, Chen FL, Zhang AM, Liu CC. Resveratrol-4-O-D(2'-galloyl)-glucopyranoside isolated from Polygonum cuspidatum exhibits anti-

Trop J Pharm Res, July 2015; 14(7): 1254 
ahepatocellular carcinoma viability by inducing apoptosis via the JNK and ERK pathway. Molecules 2014; 19: 1592-1602.

21. Zhou L, Li G, Cao B, Liu L, Cheng Q, Kong H, Shan C, Huang $X$, Chen J, Cao N. Downregulation of Mcl-1 through inhibition of translation contributes to benzyl isothiocyanate-induced cell cycle arrest and apoptosis in human leukemia cells. Cell Death Dis 2013; 4: e515.

22. Mun ST, Bae DH, Ahn WS. Epigallocatechin gallate with photodynamic therapy enhance anti-tumor effects in vivo and in vitro. Photodiagn Photodyn 2014; 11(2): 141-147.

23. Bose A, Taylor JL, Alber S, Watkins SC, Garcia JA, Rini $B I$, Ko JS, Cohen PA, Finke JH, Strorkus WJ. Sunitinib facilitates the activation and recruitment of therapeutic anti-tumor immunity in concert with specific vaccination. Int J Cancer 2011; 129(9): 21582170.

24. Hengartner MO. The biochemistry of apoptosis. Nature 2000; 407(6805): 770-776. 